Check for updates

Cite this: Nanoscale Adv., 2019, 1, 3948

\title{
A feasible strategy to prepare quantum dot- incorporated carbon nanofibers as free-standing platforms $\uparrow$
}

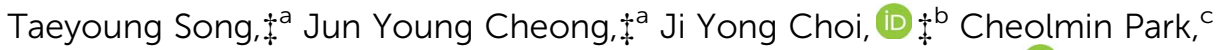 \\ Chulhee Lee, ${ }^{a}$ Changsoo Lee, ${ }^{a}$ Hyuck Mo Lee, ${ }^{a}$ Sung-Yool Choi, (DD ${ }^{c}$ \\ Hyunjoon Song, (D) *b Il-Doo Kim (D) *a and Duk Young Jeon (iD) *a
}

\begin{abstract}
Recently, quantum dots (QDs) have often garnered significant attention and have been employed for various applications. Nevertheless, most conventional devices utilize a glass substrate and/or brittle substrate, which is not compatible with next-generation wearable electronics. A suitable method for devising conductive and flexible free-standing platforms that can be combined with various kinds of QDs is thus in great need for next-generation wearable electronics. In this work, we introduce a universal and simple method to coat QDs on carbon nanofibers (CNFs) by a dip-coating process, where many kinds of QDs can be well decorated on the surface of CNFs. As one potential application among many, QDcoated CNFs were examined for their photocatalytic applications and characterization. As a result, it was found that the best performance of CdSe QD-coated CNFs for hydrogen production was 3.8 times higher than that of only QDs with the same $1 \mathrm{mg}$ of QDs. This is an early report on fabricating various kinds of QD-coated CNFs, which can be extended to a myriad set of applications.
\end{abstract}

Received 4th July 2019

Accepted 24th August 2019

DOI: $10.1039 / \mathrm{c} 9 \mathrm{na00423h}$

rsc.li/nanoscale-advances
With the emergence of the IoT technology, wearable/flexible electronics have received tremendous attention. ${ }^{11,12}$ For such technology, it is critical to use a conductive free-standing platform. In lieu of these trends, a majority of devised optoelectronics have been based on brittle substrates, ${ }^{4-6,9,10}$ although some literature has been reported on wearable/flexible substrates. ${ }^{8}$ A facile strategy to make a QD-conductive freestanding substrate needs to be devised to establish a milestone for next-generation electronic devices.

Among the materials for free-standing substrates, carbon nanofibers (CNFs), simply prepared using electrospinning, have the advantage of being low cost and have been highlighted. CNFs have been studied as a structure coated with various materials such as $\mathrm{Co}_{4} \mathrm{~N}, \mathrm{WS}_{2}, \mathrm{CdS}, \mathrm{ZnO}, \mathrm{AgS} \mathrm{S}_{2}, \mathrm{TiO}_{2}$, and $\mathrm{ZnIn}_{2} \mathrm{~S}_{4}$ and so on. Most of these coated structures have been formed by allowing materials to grow and crystallize on the surface of CNFs using various methods. ${ }^{13-20}$ The methods include the solvothermal method, the hydrothermal method, successive ionic layer adsorption and reaction, and heat treatment under specific gas-flowing conditions. ${ }^{\mathbf{1 3 - 1 8 , 2 1 , 2 2}}$ However, these methods have disadvantages in that they involve a difficult synthesis process, result in problematic surface uniformity, and are not amenable to mass production. The mechanical and physical properties of CNFs also change due to the additional chemical reaction.

In this work, we firstly suggest a highly facile CNF platform coated with various QDs using a simple dip-coating process. The dip-coating is universal and scalable, and it can be used for 
large-scale production, so that large-scale preparation of QDcoated CNFs is feasible and various kinds of QDs can be readily coated onto CNFs. QDs have changeable band gap properties, and fabricated QD-coated CNFs have the merit of adjustable energy levels of heterojunctions between the QDs and the CNFs, something which is also useful in optoelectronics. ${ }^{5}$ As one suitable application, QD-coated CNF structures were applied to photocatalytic hydrogen evolution, and the best catalytic efficiency of CdSe QD-coated CNFs was about 3.8 times higher than that of pure CdSe QDs. Additionally, the photosensitivity of the conductive and flexible free-standing structure was simply verified, and this proves useful for IoT devices due to the straightforward applicability to various shapes of reactors or devices. $^{23}$ Our work remains an early report on a feasible strategy to deposit various kinds of QDs onto a free-standing conducting carbon material, which offers the potential for numerous applications in the near future.

\section{Experimental}

\section{Materials}

Polyacrylonitrile (PAN, $M_{\mathrm{w}}=150000$ ) was purchased from Sigma Aldrich (USA). N,N-Dimethylformamide (DMF) was purchased from Sigma Aldrich (USA). CdO (99.9\%), oleic acid (OA, 90\%), 1-octadecene (1-ODE, 90\%), trioctylphosphine (TOP, $97 \%)$, and Se powder $(99.99 \%)$ were purchased from Sigma Aldrich. PbO (99.99\%), bis(trimethylsilyl)sulfide ((TMS) $)_{2} \mathrm{~S}$, synthesis grade), $\mathrm{InCl}_{3}$ (98\%), $\mathrm{ZnCl}_{2}$ (97\%), oleylamine (70\%), tris(dimethylamino)phosphine (P(DMA), 97\%), 1-dodecanethiol (DDT, 98\%), CuI (99.999\%), indium acetate (99.99\%), zinc acetate (99.99\%), sulfur (99.998\%), zinc diethyldithiocarbamate (Zn DDTC, 97\%), cadmium acetate (99.995\%), ZnO (99.999\%), sodium sulfide nonahydrate (98+\%), and sodium sulfite $(\geq 98 \%)$ were purchased from Sigma Aldrich.

\section{Synthesis of CNFs}

The synthesis of CNFs was similar to what was previously reported. ${ }^{24} 1200 \mathrm{mg}$ of PAN was dissolved in $10000 \mathrm{mg}$ of DMF, and the mixture was stirred for $24 \mathrm{~h}$ at $80{ }^{\circ} \mathrm{C}$ to allow complete dissolution. The electrospinning was conducted with the following conditions: $15 \mathrm{kV}$ applied voltage, $20 \mu \mathrm{L} \mathrm{mL}{ }^{-1}$ flow rate, 25 Gauge needle, and $15 \mathrm{~cm}$ distance between the collector and the tip of the syringe. It was stabilized under air at $280{ }^{\circ} \mathrm{C}$ for $2 \mathrm{~h}$ with a ramp rate of $2^{\circ} \mathrm{C} \mathrm{min}^{-1}$. Then, the $\mathrm{CNFs}$ were later carbonized under an $\mathrm{Ar}$ atmosphere at $900{ }^{\circ} \mathrm{C}$ for $2 \mathrm{~h}$ with a ramp rate of $5{ }^{\circ} \mathrm{C} \min ^{-1}$.

\section{Synthesis of CdSe QDs}

$150 \mathrm{mg}$ of CdO, $1.5 \mathrm{~mL}$ of OA and $20 \mathrm{~mL}$ of 1-ODE were loaded into a $100 \mathrm{~mL}$ three-neck flask. The mixture was degassed under high vacuum for $2 \mathrm{~h}$ at $130{ }^{\circ} \mathrm{C}$ and then heated to $300{ }^{\circ} \mathrm{C}$ under an $\mathrm{Ar}$ atmosphere. At this temperature, $20 \mathrm{mg}$ of Se powder dissolved in $1 \mathrm{~mL}$ of TOP was quickly injected into the solution. After $3 \mathrm{~min}$, the solution was cooled down to room temperature.

\section{Synthesis of PbS QDs}

$900 \mathrm{mg}$ of $\mathrm{PbO}, 4 \mathrm{~mL}$ of $\mathrm{OA}$, and $20 \mathrm{~mL}$ of 1-ODE were loaded into a $100 \mathrm{~mL}$ three-neck flask and heated to $120{ }^{\circ} \mathrm{C}$ under vacuum for $2 \mathrm{~h}$. After the flask was filled with $\mathrm{Ar}, 0.4 \mathrm{~mL}$ of (TMS) ${ }_{2} \mathrm{~S}$ diluted in $10 \mathrm{~mL}$ of 1-ODE was rapidly injected. Then the flask was separated from the heating mantle and naturally cooled down to room temperature.

\section{Synthesis of InP QDs and InP/ZnS QDs}

$40 \mathrm{mg}$ of $\mathrm{InCl}_{3}, 300 \mathrm{mg}$ of $\mathrm{ZnCl}_{2}$, and $14 \mathrm{~mL}$ of oleylamine were loaded into a $100 \mathrm{~mL}$ three-neck flask and heated to $120{ }^{\circ} \mathrm{C}$ under vacuum for $2 \mathrm{~h}$. Then the solution was heated to $250{ }^{\circ} \mathrm{C}$ under an Ar atmosphere. At $250{ }^{\circ} \mathrm{C}, 0.3 \mathrm{~mL}$ of $\mathrm{P}(\mathrm{DMA})_{3}$ was swiftly injected into the solution. After $5 \mathrm{~min}$, InP QDs were synthesized. For the growth of the $\mathrm{ZnS}$ shell, $3 \mathrm{~mL}$ of DDT was injected slowly into the solution and the temperature was maintained at $250{ }^{\circ} \mathrm{C}$ for $6 \mathrm{~h}$. Then the solution was cooled down to room temperature.

\section{Synthesis of CuInS ${ }_{2}$ QDs and $\mathrm{CuInS}_{2} / \mathrm{ZnS}$ QDs}

$38 \mathrm{mg}$ of CuI, $58 \mathrm{mg}$ of indium acetate, $2 \mathrm{~mL}$ of DDT, and $16 \mathrm{~mL}$ of 1-ODE were loaded into a $100 \mathrm{~mL}$ three-neck flask. After being degassed under high vacuum for $2 \mathrm{~h}$ at $120^{\circ} \mathrm{C}$, the solution was heated to $210{ }^{\circ} \mathrm{C}$ and maintained for 90 min under an Ar atmosphere. Then the solution was cooled down to room temperature. This solution contains $\mathrm{CuInS}_{2}$ QDs. For the growth of the ZnS shell, the crude solution needed a purification process, which is a simple precipitation/dispersion method. After the purification process, $20 \mathrm{mg}$ of $\mathrm{CuInS}_{2}$ QDs, $55 \mathrm{mg}$ of zinc acetate, and $5 \mathrm{~mL}$ of DDT were loaded into a $100 \mathrm{~mL}$ flask and heated to $60{ }^{\circ} \mathrm{C}$ under vacuum for $40 \mathrm{~min}$. Then the flask was heated to $280{ }^{\circ} \mathrm{C}$ and maintained for 20 min under Ar gas.

\section{Synthesis of CdS QDs}

$128 \mathrm{mg}$ of $\mathrm{CdO}, 2 \mathrm{~mL}$ of $\mathrm{OA}$ and $12 \mathrm{~mL}$ of 1-ODE were loaded into a $100 \mathrm{~mL}$ three-neck flask and heated to $130{ }^{\circ} \mathrm{C}$ for $2 \mathrm{~h}$ under high vacuum. Then the temperature was set at $250{ }^{\circ} \mathrm{C}$ under an Ar atmosphere. At $250^{\circ} \mathrm{C}, 16 \mathrm{mg}$ of $\mathrm{S}$ powder dissolved in $2 \mathrm{~mL}$ of 1 -ODE was injected into the solution. After $10 \mathrm{~min}$, the temperature was reduced at room temperature.

\section{Synthesis of red-emitting CdSe/ZnS QDs}

$820 \mathrm{mg}$ of $\mathrm{CdO}, 6 \mathrm{~mL}$ of OA, and $10 \mathrm{~mL}$ of 1-ODE were loaded into a three neck flask and heated to $130{ }^{\circ} \mathrm{C}$ under high vacuum for $2 \mathrm{~h}$. Then the temperature was adjusted to $300{ }^{\circ} \mathrm{C}$ under an Ar atmosphere. At $300{ }^{\circ} \mathrm{C}, 30 \mathrm{mg}$ of Se powder dissolved in 0.6 $\mathrm{mL}$ of TOP was quickly injected into the flask and the temperature was maintained for $10 \mathrm{~min}$. Subsequently, the flask was cooled to $225^{\circ} \mathrm{C}$ and $140 \mathrm{mg}$ of Zn DDTC dissolved in $1.4 \mathrm{~mL}$ of TOP was injected into the flask. Then the flask was heated to $280{ }^{\circ} \mathrm{C}$ and maintained for $20 \mathrm{~min}$. 


\section{Synthesis of green-emitting CdZnSeS/ZnS QDs}

$32 \mathrm{mg}$ of cadmium acetate, $277 \mathrm{mg}$ of $\mathrm{ZnO}, 7 \mathrm{~mL}$ of OA and 15 $\mathrm{mL}$ of 1-ODE were loaded into a three-neck flask and heated to $130{ }^{\circ} \mathrm{C}$ for $2 \mathrm{~h}$ under high vacuum. Subsequently, after increasing the temperature to $300{ }^{\circ} \mathrm{C}$ under an $\mathrm{Ar}$ atmosphere and a mixture of $64 \mathrm{mg}$ of sulfur and $158 \mathrm{mg}$ of Se powder dissolved in $2 \mathrm{~mL}$ of TOP was rapidly injected into the flask. After $10 \mathrm{~min}$, the flask was cooled to $225{ }^{\circ} \mathrm{C}$ and $200 \mathrm{mg}$ of $\mathrm{Zn}$ DDTC dissolved in $2 \mathrm{~mL}$ of TOP was injected into the flask. Next, the flask was heated to $280{ }^{\circ} \mathrm{C}$ and maintained for $10 \mathrm{~min}$.

\section{Synthesis of blue-emitting CdZnS/ZnS QDs}

$1834 \mathrm{mg}$ of zinc acetate, $128 \mathrm{mg}$ of CdO, $7 \mathrm{~mL}$ of OA, and $15 \mathrm{~mL}$ of 1-ODE were loaded into a three-neck flask and heated to 120 ${ }^{\circ} \mathrm{C}$ for $2 \mathrm{~h}$ under vacuum. Then the solution was heated to 310 ${ }^{\circ} \mathrm{C}$ under an Ar atmosphere and $51 \mathrm{mg}$ of sulfur dissolved in 2.4 $\mathrm{mL}$ of 1-ODE was rapidly injected into the solution. After 12 min, $128 \mathrm{mg}$ of sulfur dissolved in $5 \mathrm{~mL}$ of OA was injected into the solution and maintained for $3 \mathrm{~h}$ at $310^{\circ} \mathrm{C}$.

\section{Purification of QDs}

The synthesized crude solution of QDs needs a purification process for devices. The purification process is a precipitation/ redispersion method. An excess amount of ethanol is added to precipitate the synthesized QDs in the solution. Then the precipitated QDs are dispersed in hexane. This process is repeated 3 times and the final precipitated QDs are redispersed in hexane at specific concentrations.

\section{Dip-coating of QDs on CNFs}

QDs were coated onto CNFs by simple dip-coating. The QD solution was produced in hexane with various concentrations such as 20, 50 and $100 \mathrm{mg} \mathrm{mL}^{-1}$. The CNFs can be cut into different sizes and dimensions, and they were immersed in each QD solution for 1 min and taken out of the solution.

\section{Characterization}

Morphological features were obtained by scanning electron microscopy (SEM, SU8230, Hitachi) and field emission transmission electron microscopy (TEM, Tecnai G2 F30 S-Twin). Energy dispersive X-ray spectroscopy (EDS) mapping images were obtained using scanning transmission electron microscopy (STEM, Tecnai F20, FEI company). Component analysis of elements was performed using a SU8230 by EDS. X-ray diffraction (XRD) patterns were recorded by using an X-ray diffractometer (SmartLab, Rigaku). UV-vis absorbance spectra were recorded by a UV-1800 and SolidSpec-3700, Shimadzu. The photoluminescence spectra were recorded by using an F-7000, Hitachi, and FL920, Edinburgh instruments. Time-correlated single photon counting (TCSPC) was performed using an FL920 with a picosecond pulsed diode laser (470 nm), EPL-470, and the luminescence decay time values were calculated by using an F900 program. The decay times of CdSe-CNF, PbS-CNF, InP$\mathrm{CNF}$ and $\mathrm{CuInS}_{2}-\mathrm{CNF}$ were measured at $582.8 \mathrm{~nm}, 1068 \mathrm{~nm}$, $671 \mathrm{~nm}$ and $730 \mathrm{~nm}$ emission wavelengths, respectively, at room temperature. The work function of CNFs was obtained using ultraviolet photoelectron spectroscopy (UPS, Axis-Supra, Kratos) with a He I (21.2 eV) light source. For photocatalytic hydrogen evolution, the as-prepared catalysts were placed in a $0.25 \mathrm{M} \mathrm{Na}_{2} \mathrm{~S} / 0.35 \mathrm{M} \mathrm{Na}_{2} \mathrm{SO}_{3}$ aqueous solution $(15 \mathrm{~mL})$, and purged with $\mathrm{N}_{2}$ gas for 15 min before irradiating with visible light by using a Xe lamp ( $300 \mathrm{~W}$, Oriel) equipped with a $10 \mathrm{~cm}$ IR water filter and a UV cut-off filter $(\lambda \geq 420 \mathrm{~nm})$. The reaction was performed with a homemade quartz flask with a total volume of $36 \mathrm{~mL}$, sealed with a rubber septum, and the product was periodically collected by using a syringe from the head space. Before the photocatalytic reaction, the samples were activated through the irradiation with visible light for $30 \mathrm{~min}$ to eliminate the surface organic compounds and purged with $\mathrm{N}_{2}$ gas again, and the product was measured by using a gas chromatograph (GC, YL6100) with a thermal conductivity detector (TCD) using argon as a carrier gas. Quantum efficiency (QE) was measured by using a $10 \mathrm{~mW}$ Thorlabs Violet $(420 \mathrm{~nm})$ mounted highpower light emitting diode (LED) light (M420L3), and calculated by using the following equation:

$$
\mathrm{QE}(\%)=\frac{n_{\mathrm{e}}}{n_{\mathrm{p}}} \times 100=\frac{2 n_{\mathrm{H}_{2}}}{n_{\mathrm{p}}} \times 100
$$

where $n_{\mathrm{e}}$ is the number of electrons utilized in the hydrogen evolution, $n_{\mathrm{p}}$ is the number of photons irradiated on catalysts, and $n_{\mathrm{H}_{2}}$ is the number of hydrogen molecules generated during the reaction. The $n_{\mathrm{e}}$ is twice the $n_{\mathrm{H}_{2}}$ because the hydrogen evolution is a two-electron process.

\section{Results and discussion}

The QDs were easily coated onto the CNF platform through dipcoating, as schematically illustrated in Fig. 1a. After the

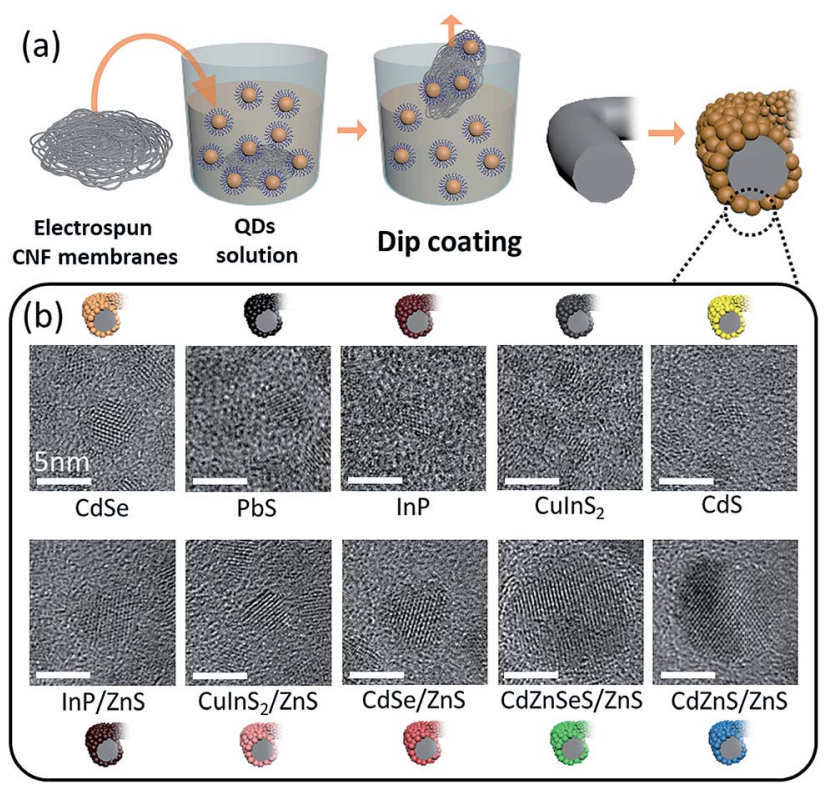

Fig. 1 (a) Schematic illustration showing the easy dip-coating process of the QD-coated CNFs and (b) TEM images showing various kinds of QDs with different atomic compositions, which were used to deposit on the surface of CNFs. 
electrospinning of the as-spun nanofibers composed of polyacrylonitrile (PAN) and subsequent heat treatments, CNFs can be fabricated easily. The QDs dispersed in either hexane, toluene, or chloroform can be easily coated onto CNFs by simple dip-coating, where QDs with ligands having an alkyl group are physically attached on the surface of CNFs by van der Waals force. ${ }^{25,26}$ QDs with various average sizes (as shown in Table S1 $\dagger$ ) can be coated directly onto the CNF scaffold, demonstrating the feasibility of the dip-coating process as a universal method to coat many different kinds of QDs onto CNFs. As suggested in Fig. 1b, various kinds of QDs with different atomic compositions can also be coated onto CNFs, where diverse functionality is expected to arise.

Scanning electron microscopy (SEM) images of pristine CNFs and various QD-coated CNFs are presented in Fig. 2. Prior to coating QDs onto CNFs, the intrinsic properties, such as the absorbance and photoluminescence (PL) spectra, of ten different kinds of QDs (CdSe, PbS, InP, CuInS ${ }_{2}, \mathrm{CdS}, \mathrm{InP} / \mathrm{ZnS}$, $\mathrm{CuInS}_{2} / \mathrm{ZnS}$, CdSe/ZnS, CdZnSeS/ZnS, and $\mathrm{CdZnS} / \mathrm{ZnS}$ ) were recorded and confirmed (Fig. S1 $\dagger$ ). The low and high magnification SEM images of pristine CNFs with a fiber thickness of about 300-500 nm are shown in Fig. 2a and b, respectively. The ten different kinds of QDs dispersed in hexane with identical concentration (20 mg mL ${ }^{-1}$ ) were easily coated onto CNFs by simple dip-coating for $1 \mathrm{~min}$ (Fig. 2c-1), although some were difficult to detect. Such a discrepancy is dependent on the particle size of individual QDs - when the size of QDs is around $10 \mathrm{~nm}$, they are visible in the SEM image, but the sizes less than $5 \mathrm{~nm}$ become difficult to detect. Based on Fig. 2c-l, it is apparent that various kinds of QDs are homogeneously coated onto the CNF surface by dip-coating. In addition, low magnification SEM images (Fig. S2 $\dagger$ ) confirm that the nanofibrous structure was well maintained after the dip-coating process, in which coating of the QDs did not alter the overall morphology. For the detailed study of electrical junction properties between the QDs and the CNFs, we chose a CdSe QD-coated CNF (denoted as CdSe-CNF) among the aforementioned QDs. To further delve into the concentration effect of QDs on the overall

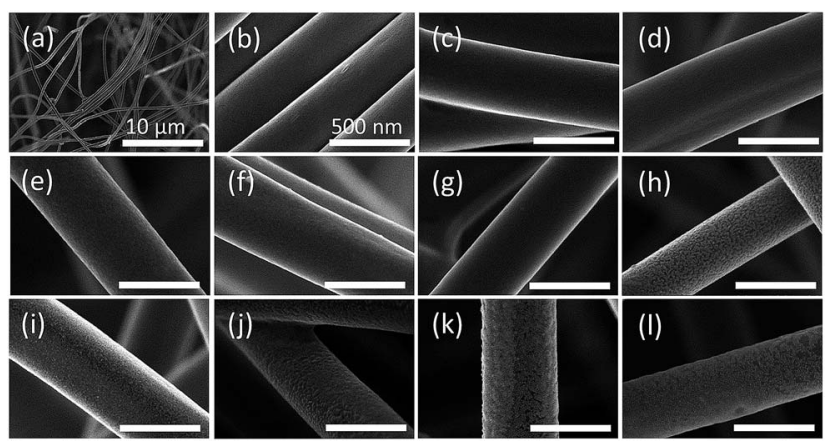

Fig. 2 SEM images of pristine CNFs in (a) low and (b) high magnification. SEM images of CNFs and CNFs coated with various kinds of QDs (20 mg mL ${ }^{-1}$ ): (c) CdSe, (d) PbS, (e) InP, (f) CIS, (g) CdS, (h) InP/ZnS, (i) CIS/ZnS, (j) CdSe/ZnS, (k) CdZnSeS/ZnS, and (l) CdZnS/ZnS. Overall surface of the hybrid composite is uniform without aggregated $Q D$ particles. degree of coating, CdSe QDs on CNFs with various coating concentrations $\left(20,50\right.$, and $100 \mathrm{mg} \mathrm{mL}^{-1}$, denoted as CdSeCNF 20, CdSe-CNF 50, and CdSe-CNF 100, respectively) were visualized through SEM images (Fig. S3†). The morphology of CNFs is not significantly altered by the coating concentration all of the samples exhibit a similar morphology, where QDs were coated on CNFs. To confirm the presence of QDs coated on CNFs, energy dispersive X-ray spectroscopy (EDS) mapping was conducted for CdSe-CNF 20 (Fig. S4†).

As the size of the QDs is generally less than $10 \mathrm{~nm}$, transmission electron microscopy (TEM) analysis was used to investigate the exact microstructure of CdSe-CNF 20 (Fig. 3). The high-resolution TEM (HRTEM) images and the corresponding selected area diffraction (SAED) pattern of CdSe QDs are shown in Fig. 3a, b, and e, revealing the successful synthesis of QDs. The low and high magnification TEM images of CdSeCNF further confirm the uniform deposition of QDs, in which a number of QDs are deposited on the surface of the CNFs (Fig. 3c and d). The CdSe-CNF SAED patterns have also shown that the crystal structures of QDs coated on the CNFs are similar to those of QDs only (Fig. 3e). To investigate the overall
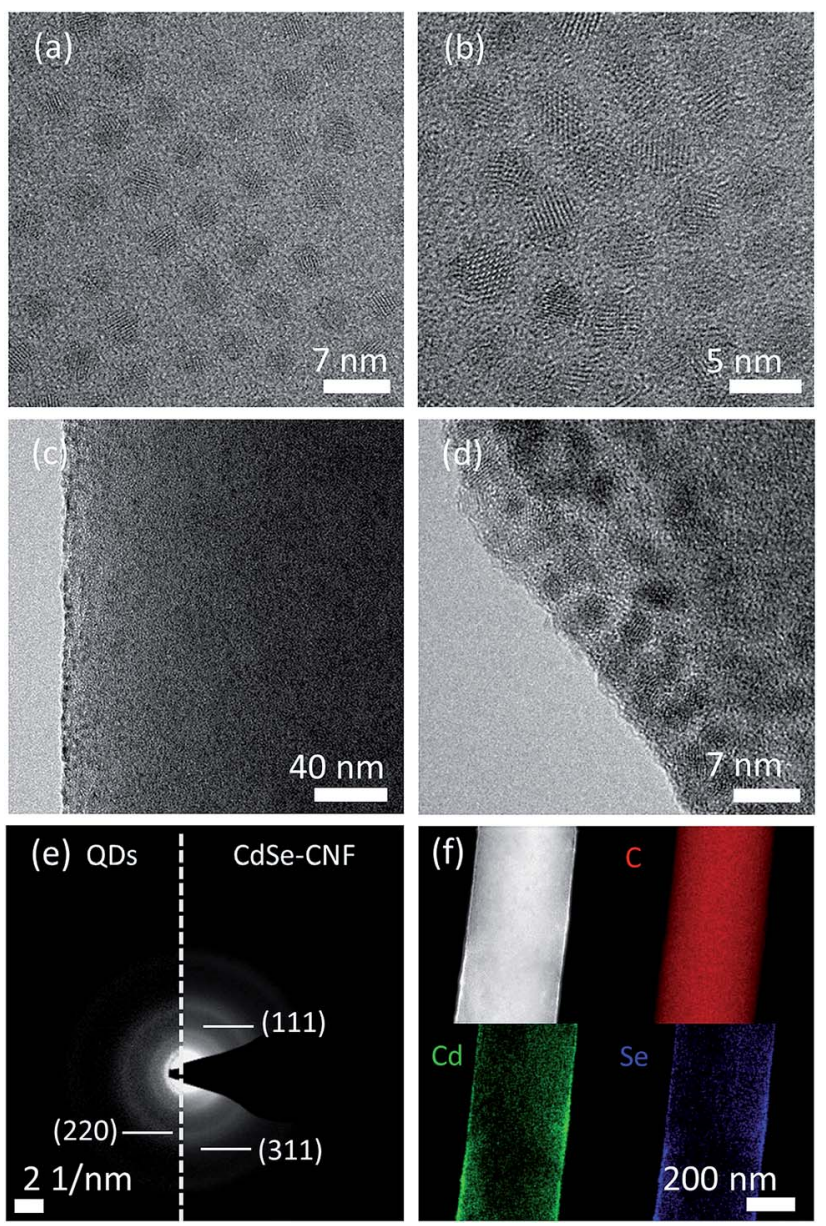

Fig. 3 (a) TEM image and (b) HRTEM image of CdSe QDs. (c) TEM image and (d) HRTEM image of CdSe-CNF 20. (e) SAED patterns of (left) CdSe QDs and (right) CdSe-CNF 20. (f) TEM-EDS mapping of CdSe-CNF 20. 
morphologies of the QD-coated surface, TEM images of CdSeCNFs with different coating concentrations were obtained, and they also exhibit similar fibrous morphologies (Fig. S5†). In Fig. 3f, TEM-EDS mapping was further conducted to confirm the deposition of CdSe-CNF. The Cd and Se are more concentrated on the edge site of the surface in the images, which can be attributed to the characteristics of EDS being more strongly influenced by the edge site. From the EDS study, we clearly confirmed the effective surface coating of QDs on the CNF surface, which was enabled by the dip-coating process. A similar trend is also observed in other QD-coated CNFs (Fig. S6†).

We also conducted quantitative and structural analyses regarding the coating concentrations of CdSe QDs. Based on the inductively coupled plasma mass spectrometry (ICP) analysis of CdSe-CNF (Table S2 $\dagger$ ) and the trend in the average amount of CdSe QDs with respect to the weight of CdSe-CNF (Fig. 4a), it is clear that both the atomic and weight ratios of $\mathrm{Cd}$ and $\mathrm{Se}$ increase with respect to $\mathrm{C}$ with the increase of the coating concentration. Based on the X-ray diffraction (XRD) patterns, when the coating concentration of CdSe QDs increases, the intensities of crystalline peaks for CdSe (ICDD no. 01-073-6987) also proportionally increase (Fig. 4b). CdSe-CNF 100 exhibits the most pronounced crystalline peaks, followed by CdSe-CNF 50 and CdSe-CNF 20. The presence of other QDs (such as InP and $\mathrm{CuInS}_{2}$ ) on the CNFs is also clearly confirmed by the XRD patterns at a coating concentration of $20 \mathrm{mg} \mathrm{mL}^{-1}$ (Fig. S7 $\dagger$ ). Furthermore, Fig. 4c shows that the coated QD layer becomes thicker with the increase of the coating loaded amount of CdSe QDs. This can be inferred from the elemental intensity of TEMEDS mapping at the edge site of the CdSe-CNFs. As mentioned previously, from the point of view of the 2D EDS mapping images, the CdSe QDs are densely located at the edge site due to the cylinder shape of the CNFs. The intensity of the Cd element is higher at the edge site than at the inner site, and Fig. 4c shows (a)

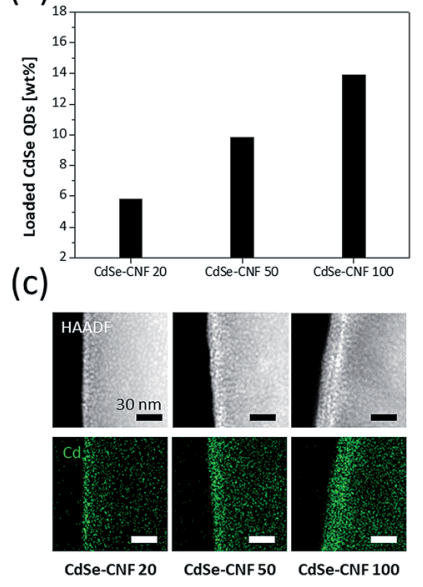

(b)

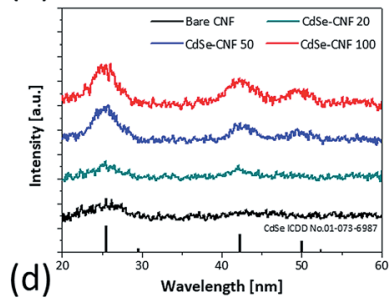

(d)

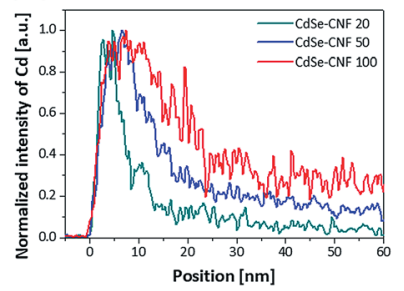

Fig. 4 (a) Ratio of CdSe QDs with respect to CdSe-CNF for different CdSe QD coating conditions. (b) XRD patterns of bare CNFs and CdSe-CNFs. (c) TEM-EDS cadmium element mapping images of $\mathrm{CdSe}-\mathrm{CNFs}$ at the edge site. (d) Normalized EDS mapping intensity of cadmium from the edge site. that the thickness of the dense Cd element region increases with the coating amount at the edge site. Other elemental mapping images are shown in Fig. S8. $\dagger$ Fig. 4d shows the intensity of the Cd element from the edge site to the inner site. As a criterion of full width at half maximum, the thicknesses of CdSe QD layers of CdSe-CNF 20, CdSe-CNF 50, and CdSe-CNF 100 are $5.4 \mathrm{~nm}, 11.7 \mathrm{~nm}$, and $18.8 \mathrm{~nm}$, respectively.

The absorbance and PL spectra of CdSe QDs dispersed in hexane are shown in Fig. 5a. The PL peak of the synthesized CdSe QDs is at $582.8 \mathrm{~nm}$. In addition, Fig. 5a shows the PL spectra of the CdSe-CNFs and a CdSe QD layer on glass. The PL intensity and PL peak of the CdSe QD layer on glass were lower and shifted to a longer wavelength, respectively, when compared with those of CdSe QDs dispersed in hexane. In the latter case, the distance between QDs is relatively shorter than the distance between QDs dispersed in hexane solution. As the distance becomes shorter, non-radiative Förster resonance energy transfer (FRET) becomes more activated between QDs, and the PL peak shifts from $583.2 \mathrm{~nm}$ to $591.1 \mathrm{~nm}$. The FRET enables excited electron-hole pairs in QDs not to emit light but to excite the other QDs in close proximity, and generates a red-

(a)

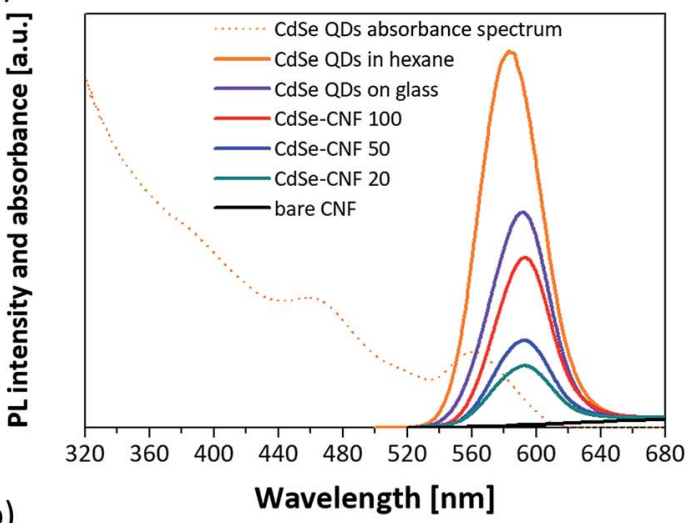

(b)

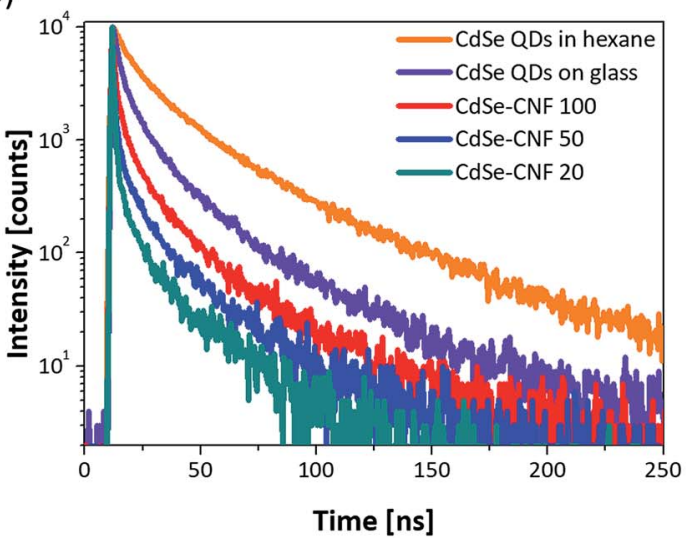

Fig. 5 (a) Absorbance and PL spectra of the synthesized CdSe QDs dispersed in hexane and PL spectra of CdSe-CNFs and a CdSe QD layer on glass. (b) Transient PL decay curves of CdSe QDs in hexane, a CdSe QD layer on glass, and CdSe-CNFs. Every characterization is performed using a source of light (excitation wavelength $=470 \mathrm{~nm}$ ). For the CdSe QD film on glass, the CdSe QDs (20 mg mL $\mathrm{mL}^{-1}$ in hexane) were spin coated on glass at $2000 \mathrm{rpm}$ for $30 \mathrm{~s}$. 
shifted PL peak and lower PL intensity. ${ }^{27-29}$ In CdSe-CNFs, as the coating concentration increases, the PL intensity becomes relatively larger due to the increased amount of coated CdSe QDs on CNFs. This trend fits the ICP analysis and the XRD patterns (Fig. 4a and b). However, the PL intensities of all CdSeCNFs are lower than the intensity of CdSe QDs in hexane, and even lower than the intensity of the CdSe QD layer on the glass substrate. In this regard, the reduced intensities of CdSe-CNFs mean that not only interaction between QDs but also interaction between QDs and CNF occurred.

To verify this, the transient PL decay times of each sample were measured. Fig. 5b shows the transient PL decay curves for each condition. In Table 1, although the decay time of the CdSe QDs dispersed in hexane is 29.93 ns, the decay time of the CdSe QD layer on glass is $16.64 \mathrm{~ns}$ due to the faster non-radiative transitions of the FRET than the radiative recombination rate of the electron-hole pairs. ${ }^{28,30,31}$ Then, the decay times of all the CdSe-CNFs are shorter than that of the CdSe QD layer on glass with insulating properties. This means that non-radiative energy transfer and/or charge transfer occur at the junction of the CdSe QDs and the CNFs. ${ }^{32}$ The charge transfer is generated by different energy level between the CdSe QD and the CNF. ${ }^{33-39}$ Fig. 6a shows the their energy levels. The LUMO and HOMO levels of CdSe QDs are $-3.44 \mathrm{eV}$ and $-5.52 \mathrm{eV}$, respectively, as obtained by cyclic voltammetry measurements (Fig. S9†).40,41 The work function of CNFs is $4.33 \mathrm{eV}$ obtained using ultraviolet photoelectron spectroscopy (Fig. S10 $\dagger$ ). Such a phenomenon can also be shown for $\mathrm{CuInS}_{2}-\mathrm{CNF}$ and InP-CNF, in which charge transfer also takes place (Fig. S11 $\dagger$ and Table S3 $\dagger$ ).

The values in Table 1 were fitted with a biexponential function composed of fast $\left(\tau_{1}\right)$ and slow $\left(\tau_{2}\right)$ decay components assigned to a radiative and a non-radiative recombination process, respectively. The fast decay component of CdSe QD solution shifts from $10.00 \mathrm{~ns}$ to $0.97 \mathrm{~ns}$ for CdSe-CNF 20, and its proportion increases from $41.64 \%$ to $58.53 \%$. The fast decay component, which is assigned to non-radiative recombination, means that the PL of CdSe QDs is quenched by the junctions. ${ }^{32,42}$ In addition, with decreasing proportion of the slow decay time component assigned to the radiative process, the PL intensity was reduced. While CdSe-CNF 20 has the shortest decay time (7.34 ns), CdSe-CNF 100 has a longer decay time of 12.15 ns. When the coating concentration is increased, the amount of coated CdSe QDs increases, and the CdSe QD layer on the CNF obviously becomes thicker. Then, the ratio of

Table 1 Fitting details of transient PL decay curves demonstrated in Fig. $5 b$

\begin{tabular}{lccccc}
\hline & & & $\begin{array}{l}\text { CdSe-CNF } \\
100\end{array}$ & \begin{tabular}{l} 
CdSe-CNF \\
\multicolumn{1}{l}{ In hexane }
\end{tabular} & $\begin{array}{l}\text { CdSe-CNF } \\
20\end{array}$ \\
\hline & On glass & 100 & \\
\hline$\tau_{1}[\mathrm{~ns}]$ & 10.00 & 4.89 & 2.29 & 1.19 & 0.97 \\
$f_{1}[\%]$ & 41.64 & 49.81 & 44.34 & 44.51 & 58.53 \\
$\tau_{2}[\mathrm{~ns}]$ & 44.15 & 28.30 & 20.00 & 16.91 & 16.32 \\
$f_{2}[\%]$ & 58.36 & 50.19 & 55.66 & 55.49 & 41.47 \\
$\tau_{\text {avg }}[\mathrm{ns}]^{a}$ & 29.93 & 16.64 & 12.15 & 9.91 & 7.34 \\
${ }^{a} \tau_{\text {avg }}=f_{1} \tau_{1}+f_{2} \tau_{2}$. & & & &
\end{tabular}
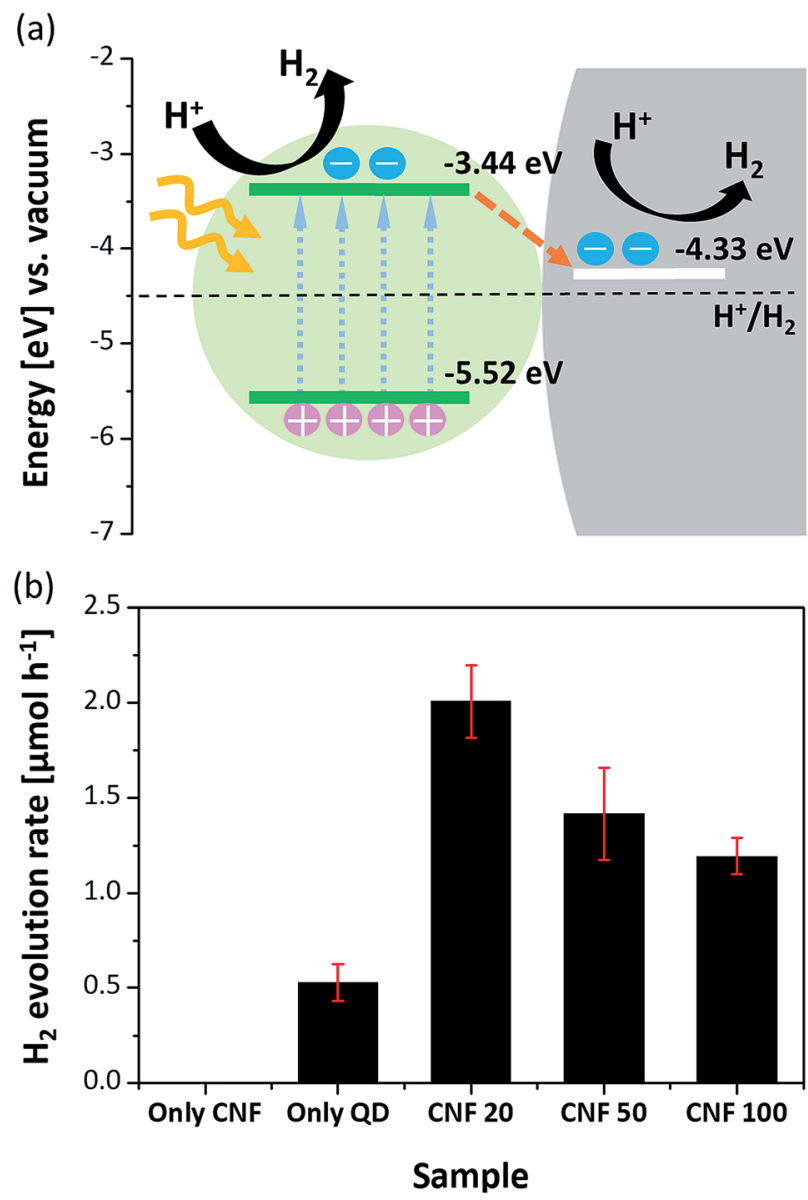

Fig. 6 (a) Energy band alignment diagram and proposed photocatalytic mechanism for CdSe-CNF. (b) Photocatalytic hydrogen evolution rates of the CNFs, CdSe QDs, and CdSe-CNFs in $0.25 \mathrm{M}$ $\mathrm{Na}_{2} \mathrm{~S} / 0.35 \mathrm{M} \mathrm{Na}_{2} \mathrm{SO}_{3}$ aqueous solution under visible light $(\lambda \geq 420 \mathrm{~nm}$ ).

additional charge transfer at the interface between the QDs and the CNF is relatively reduced and the decay time is recovered. It is expected that the charge transfer is saturated at around $10 \mathrm{mg}$ $\mathrm{mL}^{-1}$ CdSe QD concentration for dip-coating because the change of decay time from CdSe-CNF 10 to CdSe-CNF 20 is significantly larger compared with the change of decay time from CdSe-CNF 5 to CdSe-CNF 10. This means that most of the CNF surface is covered with CdSe QDs at a concentration of around $10 \mathrm{mg} \mathrm{mL} \mathrm{m}^{-1}$ (Fig. S12 and Table S4 $\dagger$ ). The junction between the QDs and the CNF, formed by the dip-coating process, is electrically well conductive and charges that are transferred to the CNF contribute to a superior performance of optoelectronics such as photocatalysts, photodetectors, sensors, and solar cells. ${ }^{22,32,38,42-49}$

To investigate the catalytic roles of the junctions that are present in CdSe-CNFs, photocatalytic hydrogen evolution was performed in an aqueous solution containing $0.25 \mathrm{M} \mathrm{Na}_{2} \mathrm{~S} / 0.35$ $\mathrm{M} \mathrm{Na}_{2} \mathrm{SO}_{3}$ as hole scavengers. CdSe QDs were chosen as the model catalyst, and the photocatalytic evolution rates were measured under the illumination of visible light $(\lambda \geq 420 \mathrm{~nm})$ using a $300 \mathrm{~W}$ Xe lamp with a UV cut-off filter. To reveal the possible effect of the hybrid system, experiments with three 
distinct CdSe-CNFs with different QD contents (CdSe-CNF 20, CdSe-CNF 50, and CdSe-CNF 100) and control experiments with CNFs alone and QDs alone were performed. The amount of catalysts was standardized to be equal based on the $1 \mathrm{mg}$ CdSe amount by ICP. As shown in Fig. 6b, the CdSe-CNFs exhibited activity superior to that of pure CdSe QDs, and the CNF alone showed no activity under visible light irradiation. ${ }^{\mathbf{1 3 , 5 0}}$ In particular, CdSe-CNF 20 showed the highest hydrogen evolution rate of $2.01 \mu \mathrm{mol} \mathrm{h}{ }^{-1}$, which was more than 3.8 times higher than that of the pure CdSe QDs $\left(0.53 \mu \mathrm{mol} \mathrm{h}{ }^{-1}\right)$. The quantum yield of CdSe-CNF 20 was estimated to be $0.39 \%$ using a $420 \mathrm{~nm}$ LED light with an intensity value of $10 \mathrm{~mW}$. In addition to measuring photocatalytic activity, a stability test was also undertaken, and it maintained the activity for three cycles of a $2 \mathrm{~h}$ reaction (Fig. S13 $\dagger$ ). Therefore, the result supported the idea that the CNF alone cannot play the role of a photocatalyst, but it can remarkably improve the photocatalytic activity. This improvement with the CNF can be explained by that the fact that the CNF induced rapid charge separation, which retarded the radiative recombination of excitons in CdSe QDs, and increased the catalytic efficiency. The expected mechanism for photocatalytic hydrogen evolution on CdSe QD-coated CNFs is as follows. Fig. 6a shows the difference in energy levels at the junction between the QDs and the CNF, and that the structure splits the photo-induced electron-hole pairs and causes electron transfer from CdSe QDs to the CNF under the illumination state. ${ }^{17,38}$ This rapid charge transfer decreases the probability of electron-hole recombination, and the remaining electrons are used for hydrogen reduction.

The ratio between QDs and CNFs significantly affects the catalytic efficiency. When comparing the three distinct samples, the amount of hydrogen production during $1 \mathrm{~h}$ irradiation was in the order of CdSe-CNF $20\left(2.01 \mu \mathrm{mol} \mathrm{h}^{-1}\right)>\mathrm{CdSe}-\mathrm{CNF} 50$ $\left(1.42 \mu \mathrm{mol} \mathrm{h}^{-1}\right)>\mathrm{CdSe}-\mathrm{CNF} 100\left(1.19 \mu \mathrm{mol} \mathrm{h}{ }^{-1}\right)$. The activity was relatively lower when the CdSe QD content was higher in the hybrid system. This was mainly caused by the thickness of the coated QD layer. As shown in Fig. 4, the thickness of the QD layer increases from about $5.4 \mathrm{~nm}$ to $18.8 \mathrm{~nm}$ with to the increase of the QD ratio, which means that the junction surface between the QDs and the CNF becomes saturated with the thicker layer. Therefore, it can be expected that in the case of CdSe-CNF 100, following visible light irradiation, a large amount of charge will remain in the QD layer instead of transferring to the CNF. Then, the electron-hole recombination amount will be larger when it is compared with that of CdSeCNF 20. This expectation can be verified through the PL decay results. As indicated in Fig. 5b, CdSe-CNF 20 had the shortest decay time and that means the largest prevalence of charge separation. Therefore, CdSe-CNF 20 had the highest photocatalytic efficiency among the CdSe-CNFs due to the optimum ratio of QDs and CNFs that reduced the electron-hole recombination and increased the active electrons for catalytic reactions.

Additionally, photosensitivity was measured using the freestanding structure of CdSe-CNF 20, and it was significantly enhanced, with the augmentation of photo-current $\left(I_{\mathrm{ph}}\right)$ with respect to dark-current $\left(I_{\text {dark }}\right)$ being almost 1.7 times greater with the introduction of CdSe QDs on CNFs (10.4\%) compared with bare CNFs $(6.3 \%)$ (Fig. S14 $\dagger$ ). Although the $I_{\text {dark }}$ is in a $\mathrm{mA}$ range which is not suitable for application in photodetectors at this stage, this structure demonstrates applicability to various optoelectronics. In accordance with the emerging trends of IoT technology, the uncomplicated coating of QDs on CNFs that can be used as a flexible/conductive free-standing substrate is tremendously expected to broaden the technical spectrum of QDs. Furthermore, the platform would be applicable to photodetectors, solar cells, and gas sensors along with photocatalysts. For these applications, it is critical to use a conductive freestanding platform.

\section{Conclusions}

In this work, for the first time, we have suggested a very comprehensive and feasible strategy to prepare a conductive and free-standing QD-coated platform by a dip-coating process. The method was tried for various kinds of QDs, and morphological analysis confirms that they were well decorated on the surface of CNFs. Compositional analyses further confirm that the deposited amount of CdSe QDs on CNFs can be tuned by the concentration of QD solution during the dip-coating. The junction properties between CdSe QDs and CNFs were investigated by PL analyses and induced charge transfer from CdSe QDs to CNFs. As one of the possible applications based on the junction, various QD-coated CNFs were tested for photocatalytic hydrogen production from water splitting. As a result, this structure shows that at the same amount of CdSe QDs (1 mg), the CdSe-CNFs exhibited higher efficiency for hydrogen production than using CdSe QDs only. Especially, CdSe-CNF 20 showed the highest hydrogen production rate of $2.01 \mu \mathrm{mol} \mathrm{h}{ }^{-1}$, more than 3.8 times compared with using the CdSe QDs only. Additionally, we verified that the free-standing CdSe-CNF platform has potential for photosensitive applications. The method suggested in this paper can be applied to various QDs, which can be extended for a number of other applications utilizing QDs as a unique physicochemical medium, such as solar cells, photodetectors, and gas sensors as well as photocatalysts.

\section{Conflicts of interest}

There are no conflicts to declare.

\section{Acknowledgements}

This research was supported by the Creative Materials Discovery Program through the National Research Foundation (NRF) of Korea funded by the Ministry of Science and ICT (NRF2016M3D1A1900035). And this work was supported by the National Research Foundation of Korea (NRF), grant no. 2014R1A4A1003712 (BRL Program), the funding from the Korea CCS R\&D Center (KCRC) grant by the Korean Government (Ministry of Science, ICT \& Future Planning) (No. NRF2014M1A8A1049303), the Wearable Platform Materials Technology Center (WMC) (NR-2016R1A5A1009926), and the NRF 
(National Research Foundation of Korea) Grant funded by the Korean Government (NRF-2017H1A2A1042006-Global Ph.D. Fellowship Program). This work was also supported by the National Research Foundation of Korea (NRF) funded by the Korean Government (MSIP) (NRF-2018R1A2B3004096 and NRF2018R1A5A1025208).

\section{References}

1 M. Nam, J. Park, S.-W. Kim and K. Lee, J. Mater. Chem. A, 2014, 2, 3978-3985.

2 Y. Shirasaki, G. J. Supran, M. G. Bawendi and V. Bulović, Nat. Photonics, 2013, 7, 13.

3 S. Pathak, E. Cao, M. C. Davidson, S. Jin and G. A. Silva, J. Neurosci., 2006, 26, 1893-1895.

4 R. Mo, Z. Lei, K. Sun and D. Rooney, Adv. Mater., 2014, 26, 2084-2088.

5 D. Kufer, I. Nikitskiy, T. Lasanta, G. Navickaite, F. H. Koppens and G. Konstantatos, Adv. Mater., 2015, 27, 176-180.

6 S. A. McDonald, G. Konstantatos, S. Zhang, P. W. Cyr, E. J. Klem, L. Levina and E. H. Sargent, Nat. Mater., 2005, 4, 138.

7 A. P. Alivisatos, Science, 1996, 271, 933-937.

8 L. Li, L. Gu, Z. Lou, Z. Fan and G. Shen, ACS Nano, 2017, 11, 4067-4076.

9 M. Chen, H. Lu, N. M. Abdelazim, Y. Zhu, Z. Wang, W. Ren, S. V. Kershaw, A. L. Rogach and N. Zhao, ACS Nano, 2017, 11, 5614-5622.

10 X. Liu, X. Ji, M. Liu, N. Liu, Z. Tao, Q. Dai, L. Wei, C. Li, X. Zhang and B. Wang, ACS Appl. Mater. Interfaces, 2015, 7, 2452-2458.

11 W. Zeng, L. Shu, Q. Li, S. Chen, F. Wang and X. M. Tao, Adv. Mater., 2014, 26, 5310-5336.

12 J. S. Heo, J. Eom, Y. H. Kim and S. K. Park, Small, 2018, 14, 1703034.

13 Y. Chen, G. Tian, Z. Ren, K. Pan, Y. Shi, J. Wang and H. Fu, ACS Appl. Mater. Interfaces, 2014, 6, 13841-13849.

14 X. Zhang, Y. Chen, Y. Xiao, W. Zhou, G. Tian and H. Fu, Nanoscale, 2018, 10, 4041-4050.

15 Y. K. Kim, M. Kim, S.-H. Hwang, S. K. Lim, H. Park and S. Kim, Int. J. Hydrogen Energy, 2015, 40, 136-145.

16 S. Yue, B. Wei, X. Guo, S. Yang, L. Wang and J. He, Catal. Commun., 2016, 76, 37-41.

17 J. Mu, C. Shao, Z. Guo, Z. Zhang, M. Zhang, P. Zhang, B. Chen and Y. Liu, ACS Appl. Mater. Interfaces, 2011, 3, 590-596.

18 K. R. Yoon, K. Shin, J. Park, S.-H. Cho, C. Kim, J.-W. Jung, J. Y. Cheong, H. R. Byon, H. M. Lee and I.-D. Kim, ACS Nano, 2017, 12, 128-139.

19 C.-L. Lee, C. Kim and I.-D. Kim, $R S C A d v .$, 2017, 7, 4480444808.

20 J.-H. Cha, S.-J. Choi, S. Yu and I.-D. Kim, J. Mater. Chem. A, 2017, 5, 8725-8732.

21 J. Y. Cheong, J.-W. Jung, D.-Y. Youn, C. Kim, S. Yu, S.-H. Cho, K. R. Yoon and I.-D. Kim, J. Power Sources, 2017, 360, 434442.
22 H. Li, H. Yu, S. Chen, H. Zhao, Y. Zhang and X. Quan, Dalton Trans., 2014, 43, 2888-2894.

23 J. Oliva, C. Gomez-Solis, L. Diaz-Torres, A. MartinezLuevanos, A. Martinez and E. Coutino-Gonzalez, J. Phys. Chem. C, 2018, 122, 1477-1485.

24 K. R. Yoon, J. Choi, S.-H. Cho, J.-W. Jung, C. Kim, J. Y. Cheong and I.-D. Kim, J. Power Sources, 2018, 380, 174-184.

25 C. Murray, C. Kagan and M. Bawendi, Science, 1995, 270, 1335-1338.

26 D. Jariwala, T. J. Marks and M. C. Hersam, Nat. Mater., 2017, 16, 170.

27 J. J. Choi, J. Luria, B.-R. Hyun, A. C. Bartnik, L. Sun, Y.-F. Lim, J. A. Marohn, F. W. Wise and T. Hanrath, Nano Lett., 2010, 10, 1805-1811.

28 R. Koole, P. Liljeroth, C. de Mello Donegá, D. Vanmaekelbergh and A. Meijerink, J. Am. Chem. Soc., 2006, 128, 10436-10441.

29 L. Sun, J. J. Choi, D. Stachnik, A. C. Bartnik, B.-R. Hyun, G. G. Malliaras, T. Hanrath and F. W. Wise, Nat. Nanotechnol., 2012, 7, 369.

30 M. Achermann, M. A. Petruska, S. A. Crooker and V. I. Klimov, J. Phys. Chem. B, 2003, 107, 13782-13787.

31 S. Crooker, J. Hollingsworth, S. Tretiak and V. I. Klimov, Phys. Rev. Lett., 2002, 89, 186802.

32 I. V. Lightcap and P. V. Kamat, J. Am. Chem. Soc., 2012, 134, 7109-7116.

33 J. Lim, B. G. Jeong, M. Park, J. K. Kim, J. M. Pietryga, Y. S. Park, V. I. Klimov, C. Lee, D. C. Lee and W. K. Bae, Adv. Mater., 2014, 26, 8034-8040.

34 P. P. Jha and P. Guyot-Sionnest, J. Phys. Chem. C, 2010, 114, 21138-21141.

35 X. Dai, Z. Zhang, Y. Jin, Y. Niu, H. Cao, X. Liang, L. Chen, J. Wang and X. Peng, Nature, 2014, 515, 96.

36 K.-T. Kuo, D.-M. Liu, S.-Y. Chen and C.-C. Lin, J. Mater. Chem., 2009, 19, 6780-6788.

37 B. S. Mashford, M. Stevenson, Z. Popovic, C. Hamilton, Z. Zhou, C. Breen, J. Steckel, V. Bulovic, M. Bawendi and S. Coe-Sullivan, Nat. Photonics, 2013, 7, 407.

38 Z. Zheng, L. Gan, J. Zhang, F. Zhuge and T. Zhai, Adv. Sci., 2017, 4, 1600316.

39 J. Yu, T. Ma and S. Liu, Phys. Chem. Chem. Phys., 2011, 13, 3491-3501.

40 S. N. Inamdar, P. P. Ingole and S. K. Haram, ChemPhysChem, 2008, 9, 2574-2579.

41 S. K. Haram, A. Kshirsagar, Y. D. Gujarathi, P. P. Ingole, O. A. Nene, G. B. Markad and S. P. Nanavati, J. Phys. Chem. C, 2011, 115, 6243-6249.

42 K.-A. Tsai and Y.-J. Hsu, Appl. Catal., B, 2015, 164, 271-278. 43 S. Min, J. Hou, Y. Lei, X. Ma and G. Lu, Appl. Surf. Sci., 2017, 396, 1375-1382.

44 K. Woan, G. Pyrgiotakis and W. Sigmund, Adv. Mater., 2009, 21, 2233-2239.

45 Y.-X. Pan, J.-B. Peng, S. Xin, Y. You, Y.-L. Men, F. Zhang, M.-Y. Duan, Y. Cui, Z.-Q. Sun and J. Song, ACS Sustainable Chem. Eng., 2017, 5, 5449-5456. 
46 G. Konstantatos, M. Badioli, L. Gaudreau, J. Osmond, M. Bernechea, F. P. G. De Arquer, F. Gatti and F. H. Koppens, Nat. Nanotechnol., 2012, 7, 363.

47 Z. Yang, M. Wang, X. Song, G. Yan, Y. Ding and J. Bai, J. Mater. Chem. C, 2014, 2, 4312-4319.
48 D. Zhang, L. Gan, Y. Cao, Q. Wang, L. Qi and X. Guo, Adv. Mater., 2012, 24, 2715-2720.

49 Z. Sun, Z. Liu, J. Li, G. a. Tai, S. P. Lau and F. Yan, Adv. Mater., 2012, 24, 5878-5883.

50 Y. Lei, C. Yang, J. Hou, F. Wang, S. Min, X. Ma, Z. Jin, J. Xu, G. Lu and K.-W. Huang, Appl. Catal., B, 2017, 216, 59-69. 